\title{
ALOKASI KREDIT PROGRAM KEMITRAAN PELAKU USAHA KULINER MITRA BINAAN PT TELEKOMUNIKASI INDONESIA TBK WILAYAH MANADO
}

\author{
Halomoan Lumban Toruan \\ Grace Adonia Josefina Rumagit \\ Leonardus Ricky Rengkung
}

\begin{tabular}{ll}
\hline Naskah diterima melalui Website Jurnal Ilmiah agrisosioekonomi@unsrat.ac.id & $:$ Jumat, 12 Juli 2019 \\
Disetujui diterbitkan & $:$ Kamis, 25 Juli 2019 \\
\hline
\end{tabular}

\begin{abstract}
This study aims to determine the allocation of credit funds in the Partnership Program by culinary business partners of PT Telekomunikasi Indonesia Tbk, Manado Region (Program Kemitraan oleh pelaku usaha kuliner Mitra Binaan PT Telekomunikasi Indonesia Tbk Wilayah Manado). Respondents were selected on all Culinary Business Partners. The data used in this study are primary data and secondary data. Primary data was obtained through direct interviews with 14 Foster Partners (respondent) using a questionnaire. Secondary data was obtained from the office of PT Telekomunikasi Indonesia Tbk in the Manado Region, the internet through the google scholar to get electronic books, journal articles and thesis related to the research topic about the allocation of the Partnership Program Credit. The analytical tool used in this research is descriptive statistical method. The results showed that the Partnership Credit Program was not used for productive purpose or sector, namely the consumptive sector but was used for household consumption, the cost of children's education, home renovation, buying television and saving. The percentage of the Partnership Program Credit used for the productive sector was $42.18 \%$, the consumptive sector amounted to $27.75 \%$ and savings amounted to $30.07 \%$ from the total amount of loans disbursed to the amount of Rp. 369,000,000, - for a total of 14 culinary business partners. ${ }^{*}$ eprm*
\end{abstract}

Keywords: credit allocation, partnership program, culinary business, PT Telekomunikasi Indonesia Tbk Manado Region

\begin{abstract}
ABSTRAK
Penelitian ini bertujuan untuk mengetahui alokasi dana kredit Program Kemitraan oleh pelaku usaha kuliner Mitra Binaan PT Telekomunikasi Indonesia Tbk Wilayah Manado. Pemilihan responden dilakukan pada semua Mitra Binaan Usaha Kuliner. Data yang digunakan dalam penelitian ini adalah data primer dan data sekunder. Data primer diperoleh melalui wawancara langsung kepada 14 Mitra Binaan dengan menggunakan kuesioner. Data sekunder diperoleh dari kantor PT Telekomunikasi Indonesia Tbk wilayah Manado, internet melalui google scholar untuk mendapatkan buku elektronik, artikel jurnal dan skripsi yang berkaitan dengan topik penelitian tentang alokasi Kredit Program Kemitraan. Alat analisis yang digunakan dalam penelitian ini ialah metode statistik deskriptif. Hasil penelitian menunjukkan bahwa Kredit Program Kemitraan lebih banyak digunakan diluar sektor produktif yaitu sektor konsumtif yang digunakan untuk konsumsi rumah tangga, biaya pendidikan anak, renovasi rumah, membeli televisi dan ditabung. Persentase Kredit Program Kemitraan yang digunakan untuk sektor produktif sebesar $42,18 \%$, sektor konsumtif sebesar 27,75\% dan tabungan sebesar 30,07\% dari jumlah total kredit yang disalurkan sebesar Rp. 369.000.000,- untuk total responden 14 mitra binaan. ${ }^{\text {*prm* }}$

Kata kunci: alokasi kredit, program kemitraan, usaha kuliner, PT Telekomunikasi Indonesia Tbk Wilayah Manado
\end{abstract}




\section{PENDAHULUAN}

\section{Latar Belakang}

Program Kemitraan memberikan dana pinjaman dengan bunga sebesar $6 \%$ per tahun yang lebih rendah daripada bunga pinjaman Kredit Usaha Rakyat dari Perbankan yaitu sebesar 7\% (Permenko No.11 Tahun 2017) sebagai wujud kepedulian terhadap pertumbuhan ekonomi masyarakat yaitu adanya program kemitraan sebagai bagian dari corporate action. Sesuai dengan Pasal 9 Permen BUMN 09/MBU/07/2015, Program Kemitraan diberikan kepada Usaha Kecil dan Menengah (UMKM)

Pemerintah menyalurkan Program Kemitraan yang disalurkan oleh 136 Wilayah perusahaan Badan Usaha Milik Negara bertujuan untuk membiayai modal kerja dan/atau pembelian aset tetap dalam rangka meningkatkan produksi dan penjualan dan pinjaman tambahan untuk membiayai kebutuhan yang bersifat jangka pendek dalam rangka memenuhi pesanan dari rekanan usaha Mitra Binaan.

PT Telekomunikasi Indonesia Tbk Wilayah Manado adalah salah satu penyalur Program Kemitraan. PT.Telekomunikasi Indonesia Tbk adalah salah satu Badan Usaha Milik Negara (BUMN) yang bergerak di bidang layanan Jasa dan Jaringan Telekomunikasi di Indonesia yang menyalurkan Program kemitraan dan telah disalurkan ke berbagai sektor UMKM seperti industri, jasa, perdagangan, perikanan, pertanian, perkebunan dan peternakan.

Dalam penyaluran kredit perlu juga diperhatikan bahwa tolok ukur keberhasilan suatu program perkreditan tidak hanya dilihat dari aspek kemampuan penyaluran dan efektifitas pemanfaatan dana secara finansial, karena masih banyak tolok ukur lainnya yang belum dikaji seperti; kemampuan pengembalian, pengalokasian dan pemanfaatan pinjaman oleh peminjam (Syarif, 2013).

Berkaitan dengan tujuan Program Kemitraan maka perlu untuk meneliti alokasi kredit Program Kemitraan pelaku usaha Kuliner Mitra Binaan PT Telekomunikasi Indonesia Tbk Wilayah Manado. Kredit program kemitraan digunakan untuk sektor produktif yaitu meningkatkan aset, produksi dan penjualan, namun ada juga Mitra Binaan yang mengalokasikan kredit ke sektor yang lain (diluar pengembangan usaha).
Rumusan Masalah

Bagaimana alokasi kredit Program Kemitraan oleh pelaku usaha kuliner Mitra Binaan PT Telekomunikasi Indonesia Tbk Wilayah Manado untuk usahanya?

\section{Tujuan Penelitian}

Tujuan dari penelitian ini adalah untuk mengetahui alokasi kredit Program Kemitraan oleh pelaku usaha kuliner Mitra Binaan PT Telekomunikasi Indonesia TBK Wilayah Manado untuk usahanya.

\section{Manfaat Penelitian}

Adapun manfaat dari penelitian ini yaitu :

1. Sebagai tambahan pengetahuan tentang pengalokasian kredit Program Kemitraan PT Telekomunikasi Indonesia Tbk Wilayah Manado oleh Pelaku Usaha Kuliner.

2. Sebagai bahan pembelajaran bagi peneliti khususnya dan semua pihak yang berminat dalam penelitian usaha dalam bidang usaha kuliner.

3. Sebagai informasi kepada Pemerintah tentang Program Kemitraan oleh PT Telekomunikasi Indonesia Tbk di kota Manado.

\section{METODE PENELITIAN}

\section{Tempat dan Waktu Penelitian}

Penelitian ini dilaksanakan dari bulan Maret hingga April tahun 2019 bertempat di Kota Manado.

\section{Metode Pengumpulan Data}

Data yang digunakan dalam penelitian ini adalah data primer yaitu wawancara langsung dengan pelaku usaha Kuliner Mitra Binaan PT Telekomunikasi Indonesia (Persero) di kota Manado dan data sekunder yaitu data yang diambil langsung dari PT Telekomunikasi Indonesia (Persero) yang berkaitan dengan penelitian. Responden dalam penelitian ini diambil secara sensus yaitu seluruh pelaku Usaha Kuliner Mitra Binaan PT Telekomunikasi Indonesia (Persero) Wilayah Manado. Jumlah pelaku usaha kuliner Mitra Binaan PT Telekomunikasi Indonesia Tbk Wilayah Manado mulai tahun 2017 sampai dengan 2018 di kota Manado sebanyak 14 Mitra. 


\section{Konsep Pengukuran Variabel}

Adapun yang terjadi konsep pengukuran variabel dalam penelitian ini adalah sebagai berikut

1. Karakteristik Responden
a. Umur (tahun)
b. Jenis kelamin (Laki-laki/Perempuan)
c. Pendidikan
d. Pengalaman berusaha
e. Etnis

2. Mengukur Alokasi Kredit Program Kemitraan oleh Pelaku Usaha Kuliner Mitra Binaan, adapun variabel-variabel yang diukur, adalah :

a. Jumlah Kredit Program Kemitraan yang diterima oleh Pelaku Usaha Kuliner Mitra Binaan.

b. Pengalokasian Kredit

- Sektor Produktif : Digunakan sebagai modal usaha atau Investasi (Rp) (Pembelian Aset, Renovasi Kios,Sewa Kios,Beli Tanah,Untuk Usaha lain, Bahan Baku)

- Sektor Konsumtif : Digunakan sebagai keperluan pribadi (Rp) (Konsumsi Rumah Tangga,Biaya Pendidikan Anak,Renovasi Rumah Pribadi,Beli TV).

- Tabungan : Sisa dana Kredit Program Kemitraan yang tidak digunakan untuk sektor produktif maupun konsumtif (Rp).

\section{Analisis Data}

Untuk menganalisis Alokasi Kredit Program Kemitraan oleh Pelaku Usaha Kuliner Mitra Binaan di Kota Manado, dipergunakan metode statistik deskriptif.

\section{HASIL DAN PEMBAHASAN}

\section{Sejarah singkat PT Telekomunikasi Indonesia Tbk}

Pada awalnya PT Telekomunikasi Indonesia Tbk didirikan pada tahun 1882 dengan nama jawatan post telegraaf telefoon (PTT). Sebelumnya, pada tanggal 23 Oktober 1856, dimulai pengoperasian layanan jasa telegraf elektromagnetik pertama yang menghubungkan Jakarta dengan Bogor. Pada tahun 2009 momen tersebut dijadikan sebagai patokan hari lahir Telkom.

Pada tahun 1961, status jawatan diubah menjadi Perusahaan Negara Pos dan Telekomunikasi (PN Postel). Kemudian pada tahun 1965, PN Postel dipecah menjadi perusahaan negara pos dan giro (PN Pos \&
Giro) dan perusahaan negara telekomunikasi (PN Telekomunikasi) kemudian pada tahun 1974 PN Telekomunikasi diubah namanya menjadi perusahaan umum Telekomunikasi (Perumtel) yang menyelenggarakan jasa Telekomunikasi nasional maupun internasional. Pada tahun 1991 Perumtel berubah bentuk menjadi perusahaan perseroan (Persero) Telekomunikasi Indonesia berdasarkan peraturan pemerintah nomor 25 tahun 1991 dan pada tanggal 14 November 1995 dilakukan penawaran umum perdana saham Telkom. Sejak itu saham Telkom tercatat dan diperdagangkan di bursa efek Jakarta (BEJ).

Pada tahun 2001 Telkom membeli $35 \%$ saham Telkomsel dari PT Indosat sebagai bagian dari implementasi restrukturisasi industri jasa telekomunikasi di Indonesia yang ditandai dengan penghapusan kepemilikan bersama dan kepemilikan silang antara Telkom dan Indosat dan pada 23 Oktober 2009. Telkom meluncurkan "New Telkom" yang ditandai dengan penggantian identitas perusahaan.

\section{Realisasi Penyaluran Kredit Program Kemitraan Pada Pelaku Usaha Kuliner PT Telekomunikasi Indonesia (Persero) Wilayah Manado. \\ Dapat dilihat realisasi penyaluran Kredit} Program Kemitraan PT Telekomunikasi Indonesia (Persero) Wilayah Manado pada pelaku usaha kuliner berbagai sektor pada Tabel 1.

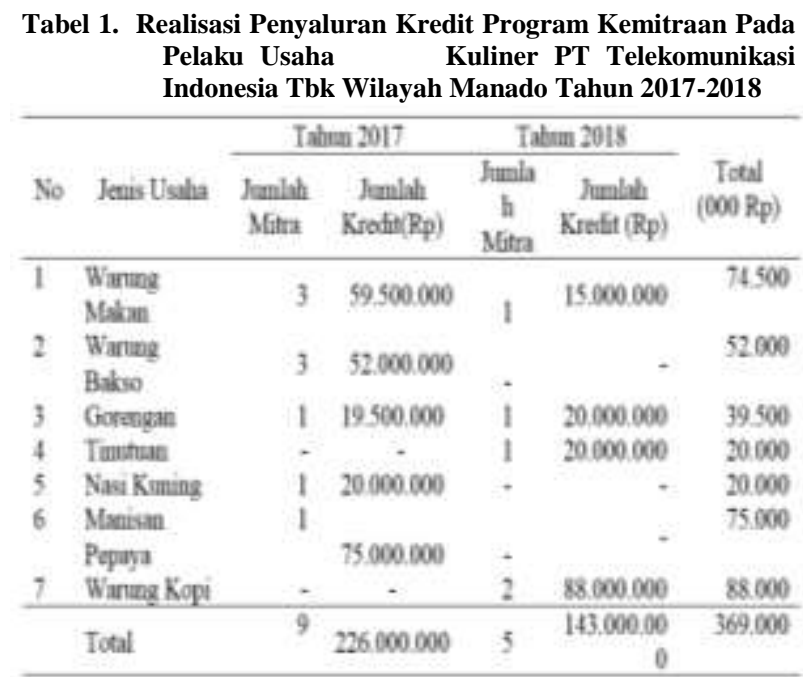

Sumber : PT.Telekomunikasi Indonesia (Persero) Manado,2019 
Tabel 1 menunjukkan bahwa Kredit Program Kemitraan disalurkan ke jenis usaha kuliner warung makan yang menjual nasi dengan macam lauk pauk, warung bakso menjual dengan gerobak dipinggir jalan, gorengan seperti Tahu isi,Tempe Goreng, Bakwan , Tinutuan, Nasi kuning dengan cara memasok ke sekolah-sekolah, Manisan Pepaya dengan cara memasok ke beberapa Supermarket yang ada di Manado dan warung kopi. Dengan bertambahnya modal yang didapatkan oleh pelaku usaha maka semakin banyak modal untuk mengembangkan usahanya, hal ini sesuai dengan Permen BUMN 09/MBU/07/2015 yaitu tujuan dari Program Kemitraan adalah untuk meningkatkan kemampuan usaha kecil agar menjadi tangguh dan mandiri.

\section{Umur}

\section{Karakteristik Responden}

Umur merupakan salah satu faktor yang mempengaruhi perilaku dalam melakukan atau mengambil keputusan dan dapat bekerja secara optimal serta produktif. Semakin bertambah umur seseorang maka akan mempengaruhi kemampuannya untuk melakukan suatu pekerjaan atau aktivitas. Seiring dengan perkembangan waktu, umur manusia akan mengalami perubahan dalam hal ini penambahan usia yang dapat mengakibatkan turunnya tingkat produktifitas seseorang dalam bekerja. Dapat dilihat pada Tabel 2.

Tabel 2. Klasifikasi responden berdasarkan tingkat umur Mitra Binaan Pelaku Usaha Kuliner PT Telekomunikasi Indonesia Tbk Wilayah Manado.

\begin{tabular}{llll}
\hline No & Umur (Tahun) & Jumlah (Orang) & Persentase (\%) \\
\hline 1 & $24-34$ & 3 & 21.43 \\
2 & $35-45$ & 6 & 42.86 \\
3 & $46-56$ & 4 & 28.57 \\
4 & $56-66$ & 1 & 7.14 \\
\hline & Jumlah & 14 & 100
\end{tabular}

Sumber : Data primer diolah, Tahun 2019

Tabel 2 menunjukkan bahwa persentase tingkat umur yang tertinggi dari responden yaitu pada umur 35-45 tahun dengan persentase 42,86 $\%$, sedangkan persentase terendah yaitu pada umur 56-66 tahun dengan persentase 7.14 \%. Hal ini menunjukkan bahwa responden yang ditemui waktu wawancara lebih banyak dalam kategori umur yang masih produktif untuk melakukan pekerjaan atau menjalankan usahanya. Hal ini sesuai dengan Nitisemito dan Burhan (2004), yang mengemukakan bahwa tenaga kerja yang umurnya masih muda kecenderungannya mempunyai fisik yang lebih kuat, sehingga diharapkan dapat bekerja keras dibandingkan dengan tenaga kerja yang umurnya lebih tua.

\section{Jenis Kelamin}

Selain faktor umur, responden dapat pula dikelompokkan berdasarkan jenis kelamin. Jenis kelamin seseorang dapat berdampak pada jenis pekerjaan yang digelutinya. Jenis kelamin juga berpengaruh terhadap produktifitas kerja seseorang. Adanya perbedaan fisik antara laki-laki dengan perempuan tentunya akan berdampak pada hasil kerjanya. Adapun klasifikasi responden berdasarkan jenis kelamin dapat dilihat pada Tabel 3 .

Tabel 3. Klasifikasi responden berdasarkan jenis kelamin Mitra Binaan pelaku usaha kuliner PT Telekomunikasi Indonesia Tbk Wilayah Manado.

\begin{tabular}{llll}
\multicolumn{4}{c}{ Indonesia Tbk Wilayah Manado. } \\
\hline No & Jenis Kelamin & $\begin{array}{l}\text { Jumlah } \\
\text { (Orang) }\end{array}$ & Persentase (\%) \\
\hline 1 & Laki-laki & 6 & 42,86 \\
2 & Perempuan & 8 & 57,14 \\
\hline & Jumlah & 14 & 100 \\
\hline
\end{tabular}

Sumber : Data primer diolah, Tahun 2019

Tabel 3 menunjukkan bahwa jumlah responden berdasarkan jenis kelamin sebagian besar adalah Perempuan dengan persentase 57,14 $\%$, sedangkan Laki-laki dengan persentase $42,86 \%$. Hal ini disebabkan karena meningkatnya kebutuhan hidup sehingga perempuan bekerja mencari pendapatan tambahan untuk keluarga.

\section{Pendidikan}

Peranan sektor pendidikan bagi suatu penduduk atau masyarakat sangat menentukan dalam rangka mencapai kemajuan dim semua bidang kehidupan, utamanya peningkatan kesejahteraannya. Tingkat pendidikan seseorang merupakan salah satu indikator yang mencerminkan kemampuan seorang untuk dapat melakukan dan menyelesaikan suatu jenis pekerjaan atau tanggung jawab yang diberikan kepadanya. Pendidikan dapat diperoleh secara formal seperti di bangku sekolah maupun non formal seperti kursus atau pelatihan. Adapun tingkat Pendidikan responden berdasarkan pendidikan Mitra Binaan pelaku usaha kuliner PT Telekomunikasi Indonesia Tbk Wilayah Manado dapat dilihat pada Tabel 4.

Tabel 4. Klasifikasi responden berdasarkan pendidikan Mitra Binaan pelaku usaha kuliner PT Telekomunikasi Indonesia Tbk Wilayah Manado.

\begin{tabular}{llll}
\hline No & Pendidikan & $\begin{array}{l}\text { Jumlah } \\
\text { (Orang) }\end{array}$ & Persentase (\%) \\
\hline 1 & SD & 1 & 7.14 \\
2 & SMP & 2 & 14.29 \\
3 & SMA & 9 & 64.29 \\
4 & D3 & 1 & 7.14 \\
5 & S1 & 1 & 7.14 \\
\hline & Jumlah & 14 & 100 \\
\hline
\end{tabular}

Sumber : Data primer diolah, Tahun 2019 
Tabel 4 menunjukkan bahwa sebagian besar responden memiliki tingkat pendidikan SMA dengan persentase $64.29 \%$ dan yang terendah adalah pendidikan SD,D3 dan S1 dengan persentase masing-masing 7,14\%. Berdasarkan data tersebut dapat disimpulkan bahwa mayoritas pelaku usaha kuliner tentang pendidikan sudah membaik. Hal ini disebabkan dengan adanya kesadaran pelaku usaha kuliner betapa pentingnya pendidikan dalam suatu usaha. Karena dengan pendidikan pelaku usaha mengenal pengetahuan, keterampilan yang berguna untuk mengelolah usahanya.

\section{Pengalaman Usaha}

Pengalaman mengelolah usaha merupakan faktor penting yang harus dimiliki oleh seorang pelaku usaha dalam meningkatkan produktifitas dan kemampuan kerjanya dalam mengelolah usahanya. Dapat dilihat pada Tabel 5.

Tabel 5. Pengalaman berusaha responden mira binaan pelaku usaha kuliner PT Telekomunikasi Indonesia Tbk.

\begin{tabular}{cccr}
\hline NO & $\begin{array}{c}\text { Pengalaman } \\
\text { Berusaha (Tahun) }\end{array}$ & $\begin{array}{c}\text { Jumlah } \\
\text { Responden } \\
\text { (Orang) }\end{array}$ & Persentase \\
\hline 1 & $1-10$ & 10 & 71.43 \\
2 & $11-20$ & 3 & 21.43 \\
3 & $21-30$ & 1 & 7.14 \\
\hline & Jumlah & 14 & 100 \\
\hline
\end{tabular}

Sumber : Data primer diolah, Tahun 2019

Tabel 5 menunjukkan bahwa persentase pengalaman berusaha paling tinggi yaitu 1-10 tahun dengan persentase $71,43 \%$, sedangkan pengalaman berusaha paling rendah yaitu 21-30 tahun dengan persentase 7,14 \%. Pelaku usaha yang memiliki pengalaman berusaha yang cukup lama umumnya memiliki pengetahuan yang lebih banyak dibandingkan dengan pelaku usaha yang baru saja menekuni usaha kuliner. Sehingga pengalaman berusaha menjadi salah satu ukuran kemampuan seseorang dapat mengelola suatu usaha kuliner. Hal ini sesuai dengan pendapat Nitisemito dan Burhan (2004), bahwa semakin banyak pengalaman maka semakin banyak pula pelajaran yang diperoleh di bidang tersebut.

\section{Etnis Mitra Binaan}

Adapun klasifikasi responden berdasarkan etnis Mitra Binaan yang menerima Kredit Program Kemitraan dari PT Telekomunikasi Tbk Wilayah Manado dapat dilihat pada Tabel 6.
Tabel 6. Klasifikasi responden berdasarkan etnis Mitra Binaan pelaku usaha kuliner PT Telekomunikasi Tbk Wilayah Manado.

\begin{tabular}{lllll}
\hline No & Etnis & $\begin{array}{l}\text { Jumlah } \\
\text { (Orang) }\end{array}$ & Persentase (\%) \\
\hline 1 & Gorontalo & 11 & 78,57 & \\
2 & Minahasa & 2 & 14,29 & \\
3 & Sunda & 1 & 7,14 & \\
\hline & Total & 14 & & 100 \\
\hline
\end{tabular}

Sumber : Data primer diolah, Tahun 2019

Tabel 6 menunjukkan bahwa etnis Mitra Binaan jenis usaha kuliner yang paling banyak adalah etnis Gorontalo yaitu 11 orang dengan persentase $78,57 \%$ dan diikuti oleh etnis Minahasa yaitu 2 orang dengan persentase $14,29 \%$, sedangkan yang paling rendah ialah etnis sunda yaitu 1 orang dengan persentase $7,14 \%$. Hal ini menunjukkan bahwa Kredit Program Kemitraan jenis usaha kuliner lebih banyak diterima oleh etnis Gorontalo.

\section{Jenis Usaha Mitra Binaan}

Kredit Program Kemitraan disalurkan oleh PT Telekomunikasi Indonesia Tbk keberbagai jenis usaha kuliner yang ada di Kota Manado. Adapun klasifikasi responden berdasarkan jenis usaha kuliner yang menerima kredit Program Kemitraan dari PT Telekomunikasi Indonesia Tbk Wilayah Manado dapat dilihat pada Tabel 7.

Tabel 7. Klasifikasi responden berdasarkan jenis usaha kuliner yang menerima Kredit Program Kemitraan dari PT Telekomunikasi Indonesia Tbk Wilayah Manado.

\begin{tabular}{llll}
\hline No & Jenis Usaha & $\begin{array}{c}\text { Jumlah } \\
\text { (Mitra } \\
\text { Binaan) }\end{array}$ & Persentase (\%) \\
\hline 1 & Warung Makan & 4 & 28,57 \\
2 & Warung Bakso & 3 & 21,43 \\
3 & Manisan Pepaya & 1 & 7,14 \\
4 & Warung Kopi & 2 & 14,29 \\
5 & Tinutuan & 1 & 7,14 \\
6 & Nasi Kuning & 1 & 7,14 \\
7 & Gorengan & 2 & 14,29 \\
\hline & Total & 14 & 100
\end{tabular}

Sumber : Data primer diolah, Tahun 2019

Tabel 7 menunjukkan bahwa jenis usaha kuliner yang paling banyak menerima Kredit Program Kemitraan ialah jenis usaha Warung Makan yaitu 4 Mitra Binaan dengan persentase sebesar $28,57 \%$, sedangkan jumlah jenis usaha kuliner yang paling sedikit menerima Kredit Program Kemitraan ialah jenis usaha Tinutuan yaitu 1 Mitra Binaan dengan persentase sebesar $7,14 \%$. 


\section{Jumlah Kredit Program Kemitraan}

Adapun klasifikasi responden berdasarkan banyaknya jumlah kredit program kemitraan yang diperoleh dari PT Telekomunikasi Indonesia Tbk Wilayah Manado dapat dilihat pada Tabel 8.

Tabel 8. Klasifikasi responden berdasarkan banyaknya jumlah kredit Mitra Binaan PT Telekomunikasi Indonesia Tbk Wilayah Manado.

\begin{tabular}{rcrr}
\hline \multirow{2}{*}{ No } & Jenis Kredit & $\begin{array}{r}\text { Jumlah (Mitra } \\
\text { Binaan) }\end{array}$ & Persentase (\%) \\
\hline 1 & $\leq 20$ juta & 12 & 85.71 \\
2 & $>20$ juta & 2 & 14.29 \\
\hline & Total & 14 & 100 \\
\hline
\end{tabular}

Sumber : Data primer diolah, Tahun 2019

Tabel 8 menunjukkan bahwa jumlah kredit program kemitraan yang paling banyak di peroleh responden pelaku usaha kuliner yaitu jenis Kredit lebih kecil atau sama dengan Rp.20.000.000 dengan persentase sebesar 85,71 $\%$, sedangkan jumlah kredit program kemitraan yang paling sedikit yaitu jenis Kredit lebih besar Rp.20.000.000 dengan persentase 14,29 $\%$. Hal ini disebabkan karena banyaknya jumlah kredit program kemitraan yang diperoleh tergantung dari kebutuhan pelaku usaha kuliner serta kemampuan pengembalian kredit tersebut. Jumlah kredit maksimum yang dapat diperoleh yaitu Rp.75.000.000.

\section{Alokasi Kredit Program Kemitraan Ke Sektor Produktif \\ Kredit Program Kemitraan yang} disalurkan oleh PT Telekomunikasi Indonesia Tbk dialokasikan ke sektor produktif yaitu digunakan sebagai tambahan modal untuk pengembangan usahanya maupun digunakan untuk investasi lainnya. Alokasi dana Kredit Program Kemitraan untuk sektor produktif dapat dilihat pada Tabel 9.

Tabel 9. Alokasi dana Kredit Program Kemitraan ke sektor produktif pelaku usaha kuliner Mitra Binaan PT Telekomunikasi Indonesia Tbk Wilayah Manado.

\begin{tabular}{|c|c|c|c|c|c|}
\hline \multirow{2}{*}{ No } & \multirow{2}{*}{ Alokasi } & \multicolumn{2}{|c|}{ Jeris Kredit } & \multirow{2}{*}{ Total } & \multirow{2}{*}{$\begin{array}{c}\text { Persentase } \\
\%\end{array}$} \\
\hline & & $\leq 20$ juta & $>20$ juta & & \\
\hline 1 & Aset & 53,265000 & 9.040 .006 & 62.305 .000 & 40.03 \\
\hline 2 & Renovasi Kios & $5,000.000$ & 3.000 .000 & 8.000000 & 5.14 \\
\hline 3 & Sewa Kios & 10.000 .000 & 0 & 10.000 .000 & 6.42 \\
\hline 4 & Beli Tamah & 17500.000 & 0 & $17.500,000$ & 11.24 \\
\hline 5 & Usala lain & 21.050 .000 & 17.000 .000 & 38.050 .000 & 24.45 \\
\hline \multirow[t]{2}{*}{6} & Bahon Babz & 9.800 .000 & $10,000.000$ & 19.800000 & 12.72 \\
\hline & Total & $116.115,000$ & 39040.000 & 155.655 .000 & 100 \\
\hline
\end{tabular}

Sumber : Data primer diolah, Tahun 2019
Tabel 9 menunjukkan bahwa kredit program kemitraan di alokasikan ke sektor produktif maupun untuk investasi yaitu membeli aset, renovasi kios, sewa kios, beli tanah, usaha lain dan untuk membeli bahan baku. Aset merupakan investasi yang dilakukan oleh Mitra Binaan untuk usahanya yaitu pembelian peralatan yang dapat menunjang pengembangan usahanya seperti pembelian gerobak bakso, etalase makanan, kursi, penanak nasi, meja, kulkas, dandang dan peralatan lainnya dalam rangka untuk meningkatkan produksi usaha Mitra Binaan.

Sewa kios merupakan investasi yang dilakukan Mitra Binaan melalui dana Kredit Program Kemitraan untuk tempat usahanya dalam rangka untuk melakukan kegiatan produksi dan penjualan. Renovasi kios merupakan investasi Mitra Binaan untuk tempat usahanya yaitu menggunakan dana Kredit Program Kemitraan untuk memperbaiki tempat usaha Mitra Binaan sehingga usahanya dapat berjalan dengan baik demi kenyamanan pembeli, seperti perbaikan lantai kios, dinding kios dan plafond kios Mitra Binaan.

Membeli tanah merupakan investasi yang dilakukan oleh Mitra Binaan dengan menggunakan Kredit Program Kemitraan, sesuai dengan hasil wawancara Mitra Binaan membeli tanah agar dana Kredit Program Kemitraan yang diperoleh tidak habis dengan percuma, tetapi masih bisa untuk dijual dan mendapatkan keuntungan. Penggunaan Kredit untuk usaha lain ialah Mitra Binaan menggunakan Kredit Program Kemitraan untuk membuka usaha baru maupun mengembangkan usaha lainnya yang dimiliki Mitra Binaan dalam rangka untuk meningkatkan pendapatan Mitra Binaan, seperti membuka usaha baru es teler, warung dan untuk mengembangkan warung Mitra Binaan dan pembelian bahan baku merupakan investasi Mitra Binaan untuk meningkatkan produksi usaha dalam rangka meningkatkan penjualan usaha Mitra Binaan.

Pada Tabel 9, juga dapat dilihat bahwa persentase Kredit yang paling banyak digunakan untuk sektor produktif ialah untuk membeli aset dengan persentase $40,03 \%$, hal ini sesuai dengan bunyi pasal 9 Permen BUMN 09/MBU/07/2015, yang mengatakan bahwa kredit program kemitraan di berikan kepada UMKM untuk meningkatkan aset pelaku usaha UMKM. 


\section{Alokasi Kredit Program Kemitraan Ke Sektor Konsumtif}

Kredit Program Kemitraan yang disalurkan oleh PT Telekomunikasi Indonesia Tbk tidak hanya dialokasikan untuk sektor produktif, tetapi Mitra Binaan juga menggunakan Kredit untuk sektor konsumtif yaitu kredit digunakan untuk keperluan pribadi Mitra Binaan. Alokasi dana Kredit Program Kemitraan untuk sektor konsumtif dapat dilihat pada Tabel 10.

Tabel 10. Alokasi Kredit Program Kemitraan ke sektor konsumtif pelaku usaha kuliner Mitra Binaan PT Telekomunikasi Indonesia Tbk Wilayah Manado.

\begin{tabular}{|c|c|c|c|c|c|}
\hline \multirow[b]{2}{*}{ No } & \multirow[b]{2}{*}{ Alokasi } & \multicolumn{2}{|l|}{ Jenis Kredit } & \multirow[b]{2}{*}{ Total (Rp) } & \multirow[b]{2}{*}{$\begin{array}{l}\text { Persentase } \\
(\%)\end{array}$} \\
\hline & & $\leq 20$ juta & $\begin{array}{l}> \\
20 \\
\text { juta }\end{array}$ & & \\
\hline 1 & $\begin{array}{l}\text { Konsumsi } \\
\text { Rumah } \\
\text { Tangga }\end{array}$ & 55.815 .000 & 0 & 55.815 .000 & 54.51 \\
\hline 2 & $\begin{array}{l}\text { Biaya } \\
\text { Pendidikan } \\
\text { Anak }\end{array}$ & 18.900 .000 & 0 & 18.900 .000 & 18.46 \\
\hline 3 & $\begin{array}{l}\text { Renovasi } \\
\text { Rumah }\end{array}$ & 25.000 .000 & 0 & 25.000 .000 & 24.42 \\
\hline 4 & $\begin{array}{l}\text { Beli } \\
\text { Televisi }\end{array}$ & 2.670 .000 & 0 & 2.670 .000 & 2.61 \\
\hline & Total & 102.385 .000 & 0 & 102.385 .000 & 100 \\
\hline
\end{tabular}

Tabel 10 menunjukkan bahwa dana Kredit Program Kemitraan dialokasikan ke sektor konsumtif yaitu untuk konsumsi rumah tangga, biaya pendidikan anak, renovasi rumah (tempat tinggal pribadi) dan untuk membeli Televisi rumah. Konsumsi rumah tangga yaitu Mitra Binaan menggunakan sebagian Kredit Program kemitraan untuk biaya makan keluarga sehari-hari, biaya pendidikan anak yaitu Mitra Binaan menggunakan sebagian Kredit Program Kemitraan untuk membiayai pendidikan anak dari Mitra Binaan yang sedang menempuh pendidikan Sekolah Menengah Atas dan Perguruan Tinggi. Alokasi Kredit untuk renovasi rumah yaitu Mitra Binaan menggunakan sebagian Kredit Program Kemitraan untuk memperbaiki rumah pribadi Mitra Binaan, sesuai dengan hasil wawancara Mitra Binaan menggunakannya untuk memperbaiki dapur rumah yang sudah rusak dan Mitra Binaan juga menggunakan Kredit untuk membeli Televisi untuk digunakan keluarga Mitra Binaan.
Pada Tabel 10 juga dapat dilihat bahwa persentase Kredit yang paling banyak digunakan untuk sektor konsumtif ialah untuk konsumsi rumah tangga (biaya makan seharihari) dengan persentase $54,51 \%$, sesuai dengan hasil wawancara dengan Mitra Binaan hal ini terjadi karena Mitra Binaan tidak selalu berjualan selama sebulan penuh disebabkan oleh berbagai faktor seperti sakit, bulan puasa dan lebaran, sehingga tidak memperoleh keuntungan dari usaha Mitra Binaan dan menggunakan Kredit Program kemitraan untuk konsumsi rumah tangga (biaya makan seharihari), sedangkan jenis kredit lebih besar dari Rp.20.000.000,- tidak ada yang menggunakan dana kredit Program Kemitraan untuk sektor konsumtif, hal ini terjadi karena Mitra Binaan menabung sisa dana kredit yang telah dialokasikan ke sektor produktif.

\section{Kredit Program Kemitraan yang ditabung Mitra Binaan.}

Kredit yang ditabung ialah Kredit Program Kemitraan yang tidak digunakan untuk sektor produktif maupun sektor konsumtif. Selain digunakan untuk produktif dan konsumtif, tetapi Mitra Binaan juga menabung Kredit Program Kemitraan yang tidak digunakan untuk sektor produktif dan sektor konsumtif. Sesuai dengan hasil wawancara dengan Mitra Binaan hal ini terjadi karena Mitra Binaan merasa kebutuhan untuk usahanya sudah tercukupi dan tidak perlu lagi untuk melakukan pembelian aset dan penggunaan untuk sektor produktif lainnya. Mitra Binaan yang menabung sebagian Kredit Program Kemitraan adalah 2 (dua) Mitra Binaan yang mendapatkan Kredit lebih besar dari Rp.20.000.000,- yaitu jenis usaha Warung Kopi sebesar Rp.65.960.000,- dan Manisan Pepaya sebesar Rp.45.000.000,- dengan total Rp.110.960.000,--

\section{Alokasi kredit Program Kemitraan Mitra Binaan Pelaku Usaha Kuliner.}

Kredit Program Kemitraan digunakan untuk sektor produktif, konsumtif dan sisanya ditabung oleh Mitra Binaan. Berikut Tabel alokasi Kredit Program Kemitraan PT Telekomunikasi Indonesia Tbk Wilayah Manado. 
Tabel 11. Alokasi Kredit Program Kemitraan pelaku usaha Mitra Binaan

PT Telekomunikasi Indonesia Tbk Wilayah Manado.

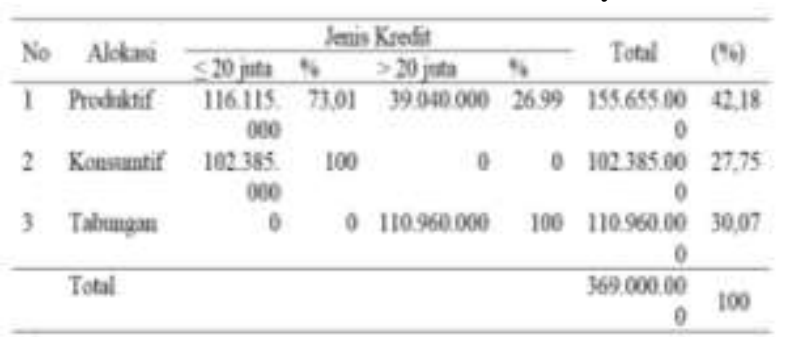

Sumber : Data primer diolah, Tahun 2019.

Tabel 11 menunjukkan bahwa dari jumlah total Kredit yang disalurkan oleh PT Telekomunikasi Indonesia Tbk Wilayah Manado yaitu sebesar Rp.369.000.000,- hanya digunakan 42,18 \% yaitu Rp.155.655.000,untuk sektor produktif oleh Mitra Binaan dan untuk sektor konsumtif sebesar $27,75 \%$ yaitu sebesar Rp.102.385.000,- dan sisanya ditabung sebesar Rp.110.960.000,- dengan persentase 30,07 \%. Hal ini menunjukkan bahwa Kredit Program Kemitraan lebih banyak digunakan diluar sektor produktif yaitu sektor konsumtif yang digunakan untuk konsumsi rumah tangga, biaya pendidikan anak, renovasi rumah, membeli Televisi dan ditabung. Maka dapat disimpulkan ada kecenderungan bahwa semakin besar kredit yang diterima oleh mitra binaan maka semakin besar Kredit yang digunakan diluar sektor produktif.

\section{KESIMPULAN DAN SARAN}

\section{Kesimpulan}

Alokasi kredit program kemitraan dari PT. Telekomunikasi Indonesia Tbk Wilayah Manado periode tahun 2017 hingga 2018, digunakan untuk sektor produktif sebesar 42,18 $\%$, sektor konsumtif sebesar 27,75 \% dan tabungan sebesar 30,07\% dari jumlah total kredit yang disalurkan sebesar Rp. 369.000.000,-.

\section{Saran}

PT. Telekomunikasi Indonesia Tbk Wilayah Manado hendaknya melakukan pengawasan lebih terhadap Mitra Binaan agar dana kredit yang diterima digunakan sesuai dengan peruntukkannya sesuai dengan Pasal 9 Permen BUMN 09/MBU/07/2015.

Mitra Binaan PT Telekomunikasi Indonesia Tbk Wilayah Manado seharusnya mengalokasikan kredit Program Kemitraan hanya untuk pengembangan usahanya saja (produktif), agar dapat meningkatkan produksi dan penjualan serta dapat mengembangkan usahanya.

\section{DAFTAR PUSTAKA}

Nitisemito, A.S dan Burhan, M.U. 2004 .Wawasan Studi Kelayakan dan Evaluasi Proyek.Penerbit Bumi Aksara, Jakarta. 